\title{
O DEBATE SOBRE A DESCENTRALIZAÇÃO DE POLÍTICAS PÚBLICAS: UM BALANÇO BIBLIOGRÁFICO
}

\author{
Maria do Carmo Lessa Guinmarães
}

Professora Adjunta da UFBA, Doutora em Administração Pública(2000) e Mestre em Saúde Comunitária (1983), pela Universidade Federal da Bahia

\section{Resumo}

O tema descentralização contempla uma variedade de entendimentos e de concepções 'valorativas' o que torna controvertido e polêmico o debate sobre ele na literatura internacional e nacional. Partindo desta constatação, este ensaio apresenta de uma forma "esquemática", como recurso metodológico, várias vertentes e linhas de abordagem possível de se encontrar na literatura sobre o tema, numa tentativa de evidenciar as distintas dimensões do conceito, seus pressupostos e justificativas, contribuindo para uma maior compreensão sobre a descentralização enquanto um fenômeno político que na contemporaneidade tem se colocado como estratégico para os projetos de Reforma de Estado. A apropriação deste leque de entendimento sobre a descentralização é também ilustrado pela autora a partir do levantamento de distintas abordagens e vertentes sobre o tema no âmbito específico da literatura da saúde no Brasil, campo considerado profícuo em termos da produção de propostas de modelos descentralizados de organização de sistemas de saúde.

\section{Abstract}

The theme of decentralization embraces many kinks of understanding and 'value' concepts, what makes the debate very controversial and polemic in national and international literature. From this evidence, this article presents "schematically", as a methodological resource, many different approaches that can be found in literature about this theme, trying to show the different dimensions of this concept, its presupposes and justifications, leading this way to a better comprehension of decentralization as a political phenomenon which, in the contemporary time, has placed itself as strategic to State's Reform's project. The appropriation of this kind of understanding about decentralization is also shown by the author from a survey of different approaches about this theme in the specific sphere of action of health literature in Brazil. This field activity is considered advantageous in terms of production of decentralized models' proposals in the organization of health systems.

\section{I - Introdução}

O tema da descentralização não é novo na literatura. Pelo contrário, há registros muito remotos de sua presença na literatura clássica, desde as obras sobre teoria do Estado até aquelas próprias do campo da Administração. Por esta razão, é notório o leque de entendimentos e de concepções que cercam o tema, o que pode também explicar as controvérsias observadas sobre ele na literatura, e a presença obrigatória de notas introdutórias sobre seus vários significados e entendimentos. $\mathrm{Na}$ verdade, falar sobre descentralização, em termos gerais, quase sempre não significa muita coisa. 
Nesse sentido, ao contemplar os diversos conceitos e o distintos tratamentos dados ao tema no âmbito da literatura, esta discussão será apresentada neste ensaio em três momentos. Inicialmente, serão apresentados os vários conceitos que a descentralização vem adquirindo no debate e quais as razões que vêm informando tais concepções ${ }^{1}$. O segundo momento apresenta, com base nesses conteúdos, como o tema da descentralização vem sendo tratado na literatura, no campo das ciências política e da administração pública (Quadro 1). Em seguida, ainda num esforço de síntese, são especificadas as diferentes tipologias do conceito observadas neste debate e os equívocos que, na visão de Boisier(1991), são os mais freqüentes na discussão sobre o tema. $O$ terceiro momento situa esta diversidade de abordagens no campo das políticas de saúde e suas implicações para as propostas de reformas políticas que vêm sendo operadas no setor saúde do país nesse fim de milênio (Quadro2).

À guisa de conclusões finais, a partir da revisão da literatura levantada, a autora ressalta a tendência atual do debate acerca do tema da descentralização.

\section{II - Da desconcentração de atividades para a transferência do poder de decisão}

O tema da descentralização nas últimas décadas transformou-se numa espécie de bandeira universal, na medida em que distintos atores, grupos e setores a aplicaram em conjunturas diferentes e na perseguição de fins diversos. Face a esta sua "propriedade", Tobar (1991) a considera um autêntico "camaleão político", posto que é defendida por distintos atores sociais com posições antagônicas, enquanto Mattos(1989) a considera uma "panacéia", defendida como solução para os mais diversos problemas das sociedades contemporâneas.

A discussão sobre a descentralização é de fato polêmica, na medida em que se trata de um processo complexo, multifacetário e geralmente gradual, estando presente em vários campos disciplinares. Segundo Penfold-Becerra(1998), a descentralização está presente em vários campos disciplinares. No campo das ciências políticas é tratada como mecanismo democrático, que permite a autonomia política dos níveis locais e regionais, com vistas ao aprofundamento da democratização. No campo das ciências econômicas, ela é vista como transferência de responsabilidades das atividades econômicas públicas para o setor privado. No campo da sociologia, a descentralização é tida como um mecanismo para a autorização ("empowerment") da sociedade civil, com o objetivo de incrementar a cidadania. Por fim, no campo da Administração Pública, ela constitui uma política para se diluir o poder decisório e administrativo dentro das agências públicas centrais, através da desconcentração, ou seja, da transferência de responsabilidade administrativa sobre os serviços básicos públicos do nível nacional para os governos regional e local (p.3-5).

É possível também identificar que esta discussão sobre a descentralização fundamentase em dois planos: um jurídico e um político-institucional. No plano jurídico, a descentralização é concebida como um processo de transferência de competências e de poderes entre órgãos, ou dentro de um mesmo órgão, enquanto sujeitos de imputação jurídica, vinculada à idéia de desconcentração, ou delegação de funções. De outro modo, a descentralização é concebida como ruptura de um vínculo hierárquico pré-existente e relaciona-se basicamente à idéia de competências exclusivas. Nesse caso, descentralização implica a ausência de intervenção de qualquer outro órgão ou instância.

No plano político - institucional, a descentralização é concebida como desagregação do poder público, através de diversas modalidades, que vão de uma simples desconcentração de atividades até a descentralização de poder decisório, ou seja, da transferência de competências ou poderes do centro para a periferia. Neste plano, é possível identificar três dimensões complementares: a administrativa, a social e a política.

\footnotetext{
${ }^{1}$ Esta discussão conceitual será sintetizada a partir da revisão feita por Piera(1992) embora não exclusivamente. A classificação sobre os planos conceituais e suas dimensões foram tomados de empréstimo desse autor.
} 
$\mathrm{Na}$ dimensão administrativa, a descentralização refere-se à delegação, ou seja, à transferência de competências e de funções entre unidades, entre esferas de governo ou entre órgãos. Esta concepção de descentralização é justificada em função da necessidade de se buscar maior eficácia na gestão pública, eliminação de intermediações burocráticas e possibilidade de um contato mais próximo com o cidadão, o que geraria maior fidelidade às demandas sociais e melhor adequação da administração ao cumprimento de seus objetivos. Assim, a descentralização facilita a relação do usuário com o Estado, simplificando a tramitação burocrática e permitindo canalizar cada demanda de forma mais singularizada e mais adaptada às suas especificidades.

$\mathrm{Na}$ dimensão social, a descentralização traduz-se como participação social na gestão pública. Trata-se de uma passagem de parcelas de poder, competências e funções, segundo o caso, da administração pública para a sociedade civil. Pode ocorrer sob diversas formas e com diversas combinações. Desse modo, a descentralização é tratada como estratégia de capacitação de grupos sociais para decidirem sobre problemas da gestão pública local, seja estruturando formas institucionais capazes de expressar a vontade coletiva nas instâncias de tomada de decisão, seja como forma de possibilitar à população exercer funções de fiscalização e controle sobre a gestão dos serviços públicos.

Além disso, a descentralização é também concebida como estratégia para o estabelecimento de modalidades de parcerias com os setores sociais, assim como de transferência, para o setor privado, da execução de tarefas antes consideradas de competência exclusiva do setor público. Esta concepção de descentralização é justificada pela necessidade de se reverter práticas paternalistas de Estado, através da democratização da gestão pública e da eliminação de intermediações burocráticas, criando novas possibilidades institucionais de participação da população organizada na prestação de serviços públicos.

$\mathrm{Na}$ dimensão política, a descentralização é uma estratégia para redistribuição do poder político do Estado, do nível central para os níveis periféricos. Baseia-se na concepção de que a descentralização afeta as relações de poder e introduz novos conflitos nas relações entre esferas de governo e na distribuição de poder e bens entre diferentes grupos na sociedade. Este entendimento fundamenta-se no conceito de descentralização enquanto processo político e é justificada como estratégia para democratização do poder, através da ampliação dos níveis de participação cidadã e da multiplicação de estruturas de poder, com vistas à melhoria da eficiência da gestão pública.

Diante disso, é possível verificar que o debate acerca da descentralização envolve várias dimensões e pode ser aplicada em vários contextos. Nas discussões contemporâneas sobre a restruturação do Estado, ela vem sendo concebida tanto como mecanismo de redução das funções básicas e indispensáveis do Estado, quanto como sinônimo de democratização da administração pública, da burocracia e dos partidos, através da multiplicação de estruturas de poder. Isto significa um continuum, que vai da simples transferência de competências a uma complexa restruturação do poder decisório (Castro,1991).

Neste ensaio, a revisão da literatura ${ }^{2}$ privilegiou a discussão sobre o tema no âmbito da esfera governamental, por ser este o que se relaciona mais diretamente com o campo das Ciências Políticas e da Administração Pública. Nesses campos, a partir da revisão realizada, é possível identificar duas grandes vertentes de análise ${ }^{3}$ sobre o tema: uma que trata dos

\footnotetext{
${ }^{2}$ A revisão de literatura aqui realizada não pretende dar conta do conjunto dos trabalhos produzidos sobre o tema da descentralização em geral e da saúde em particular (analisada em seguida no item IV deste ensaio), o que de resto seria uma tarefa, se não impossível, extremamente exaustiva. Assim, é importante deixar claro que os trabalhos aqui referidos devem ser vistos como ilustrações deste debate e sua seleção não obedeceu a nenhum critério valorativo.

${ }^{3}$ Optou-se pela categorização dos estudos sobre o tema em vertentes, por considerá-la mais apropriada à situação, na medida em que se verificou, na revisão da literatura, que um mesmo autor trata o tema descentralização sob diferentes ângulos. Nesse caso, o que existe, principalmente, é o privilegiamento em determinados trabalhos de um tipo de enfoque sobre o tema, o que não significa, necessariamente, a adoção de uma determinada concepção de descentralização, situação que pode ocorrer em alguns casos, mas não é a regra geral.
} 
aspectos mais procedimentais da descentralização, ou seja, a sua dimensão administrativa, e outra que aborda o lado processual, ou seja, sua dimensão social e política (Quadro 1).

$\mathrm{Na}$ primeira vertente, a descentralização é discutida a partir de questões dela decorrentes, como a transferência de recursos financeiros ou de competências formais para as unidades sub-nacionais de governo (Afonso e Lobo, 1996; Costa,1986; Davidovich,1993; Filho,C.P et al,1993; IPEA,1994; Lavina et al,1995; Lordello de Melo,1991; Lobo,1993; Rufian,1992; Rezende,1984 e 1993; Sato,1993b). Sob outra ótica, discute-se a descentralização quanto às suas implicações administrativas e institucionais para as esferas locais de governo em países federais (Almeida, 1996; Afonso e Silva,1996; Borja, 1987; Borgonov,1985; Dowbor, 1993; Felicíssimo,1992; Sato,1990 e 1993 a; Souza,C,1990; Zancheti,1986; Rabi,1993).

$\mathrm{Na}$ segunda vertente, que aborda o lado processual e a dimensão social e política do fenômeno da descentralização, são identificadas três linhas de estudos sobre o tema. A primeira delas considera a descentralização como estratégia para se aumentar a participação social no processo de formulação, implementação e controle das políticas públicas, analisando os limites e possibilidades das transferências de poder decisório para os níveis locais de governo em determinados contextos sociais (Baêta,1989; Borja,1988; Castro,1991; Coelho,1993; Daniel,1988; Felicíssimo,1994; Jacob,1990 e 1991; Massolo,1988; Souza,C,1992; Spink,1993; Uga,1991; Motta,1994).

A segunda linha desta vertente reafirma a descentralização como fenômeno político de natureza processual, que envolve distribuição territorial do poder do Estado, convertendo-se, portanto, em geradora de conflitos e constrangimentos decorrentes da introdução de novos atores sociais e de novos interesses em um contexto de reformas políticas ${ }^{4}$. Suas repercussões são analisadas não só no plano das relações intergovernamentais como no plano das relações societárias, face à distribuição de poder e bens do Estado entre diferentes grupos na sociedade (Arocena,1989 e 1991, Bennett,1990; Borja,1984; Fleury,1990; Preteicelle,1988; Souza, C,1995 e 1996; Tobar,1991; Vieira,1971).

É importante destacar, no âmbito desta vertente, o estudo de $\operatorname{Smith}(1985)$ sobre a descentralização, considerado uma obra clássica pela abrangência do aporte teórico dado ao tema. Smith (1985) considera que a descentralização é hoje uma demanda universal. Ela pode ser aplicada em várias circunstâncias e nas mais diversas organizações, envolvendo a combinação hierárquica de diferentes instituições e funções, e é vista contemporaneamente como uma condição necessária para o desenvolvimento social, econômico e político dos Estados Modernos. Por esta razão, o autor admite que o estudo da descentralização diz respeito à distribuição territorial de poder e envolve principalmente a influência das ciências políticas e da administração pública.

Do mesmo modo, é necessário registrar que o tema da descentralização e centralização é parte obrigatória dos tratados clássicos de Ciências Políticas, enquanto forma de organização territorial do poder do Estado. Assim, por exemplo, a obra de Burdeau (1980) apresenta uma discussão sobre os fundamentos da descentralização e centralização e critica a imprecisão com que estes conceitos são apresentados. Mesmo não sendo conceitos absolutos, argumenta que a descentralização combina com a centralização muito mais do que a suprime, concluindo ser a descentralização essencialmente uma forma de organização do poder que permite adaptar as condições de formação dos sistemas políticos (p.391).

\footnotetext{
4 Segundo Arocena (1989), os trabalhos sob esta orientação debatem concepções distintas acerca da viabilidade da descentralização em contextos históricos e políticos específicos, os quais, por sua vez, refletem diferentes concepções teóricas sobre modelo de sociedade, de Estado e de desenvolvimento. Por esta razão, o debate sobre o tema descentralização para este autor envolve 4 eixos conceituais: 1) concepção de modelo de desenvolvimento - polarizam as visões estruturalistas e micro-desenvolvimentistas; 2) concepção sobre sistema de decisão - debatem as visões elitistas e basistas; 3) concepção sobre o modo de organização do território - confrontam as visões localistas e centralistas e 4) concepção sobre a definição do agente do desenvolvimento - debatem as visões estatistas versus privatistas.
} 
Mais recentemente, no bojo do debate contemporâneo sobre reforma do Estado, a descentralização vem ocupando um espaço privilegiado, propiciando o surgimento de novos trabalhos que reforçam a natureza política e processual da descentralização. Tais estudos buscam analisar as razões pelas quais a descentralização é estratégica no processo de reforma de Estado, assim como o caráter mítico que se observa em torno de suas potencialidades para a busca da eficiência das políticas públicas. Neles, a descentralização é analisada como mecanismo de redução das funções básicas e indispensáveis do Estado e como sinônimo de democratização da administração pública, da burocracia e dos partidos, através da multiplicação das estruturas de poder. Vale registrar a publicação organizada pelo Instituto Latino Americano y del Caribe de Planificación Económica y Social - ILPES - (1994), contendo uma coletânea de documentos apresentados no Seminário Internacional de Reforma e Modernização do Estado e da IX Conferência de Ministros e Chefes de Planejamento na América Latina, a qual tem a descentralização como eixo central das discussões apresentadas.

É nesta linha de trabalhos teóricos que também se identifica uma presença maior de estudos críticos sobre a descentralização como estratégia de reação aos regimes autoritários e centralizadores, em particular nos países da América Latina, constituindo-se, portanto, como indutora da democracia e do desenvolvimento regional, com forte dependência dos fatores políticos, conjunturais e culturais (Mattos,1989, Arretche,1996, D’Arc,1992, Medeiros,1983, Prud'homme,1995, Souza, M.T.A de, 1997). De outro modo, também identifica-se nesta linha de abordagem, estudos sobre os processos de descentralização em países unitários como a França (Gontcharroff,1991,Mabileau,1992, Rosavallon,1993), Espanha e outros países latinos como o México ( François D’Arcy et Baena Alcazar, 1986), com destaque para os trabalhos de Nohlen (org.) (1991) e de Revel-Mouroz (coord.)(1989), que trazem um conjunto de textos com análises comparativas dos processos de descentralização na Europa e América Latina.

A terceira linha de trabalho, dentro desta mesma vertente, discute a proximidade entre os conceitos de descentralização e federalismo, focalizando a descentralização como transferências intergovernamentais, principalmente em países federais. Embora não se trate de uma discussão recente, surge com mais vigor, nos últimos anos desta década, principalmente no âmbito da literatura internacional, quando verifica-se o retorno das idéias federalistas e sua relação com os projetos de descentralização promovidos em Estados unitários como a França e Espanha (Heraud,1983; Xavier-Aubry,1992; Mecheut,1994; Ziccardi,1996). Isso vem se dando especialmente na Europa, face às discussões sobre a unificação européia, que tem colocado a questão da organização do Estado no centro dos debates. De forma geral, trata-se de trabalhos que discutem o conceito de descentralização associado ao de federalismo, seja para estabelecer diferenças ou pontos convergentes entre os dois conceitos, seja ainda para analisar os efeitos da descentralização de políticas sociais em sistemas federativos, além dos limites e possibilidades das propostas de descentralização em estados unitários e federais (Penfold-Becerra,1998; Elazar,1981; Arretche,1998; Sousa,C,1998).

\section{III - As tipologias da descentralização}

É constante também encontrar na literatura um elenco de tipologias acerca da descentralização. Sua construção se dá justamente a partir da compreensão que se tem sobre o tema. Assim, encontram-se tipologias construídas sobre concepção de descentralização enquanto mecanismo de transferência de decisão e tipologias que contemplam modalidades distintas de descentralização, de acordo com os objetivos que se pretende alcançar com sua implementação. São os seguintes os 'tipos' de descentralização apresentados na literatura ${ }^{5}$,

\footnotetext{
${ }^{5}$ São vários os autores que se referem a estes tipos ou modalidades de descentralização, sendo difícil identificar uma única autoria. Contudo, esta síntese se baseia em Penfold-Becerra(1998).
} 
segundo o nível para o qual a tomada de decisão é transferida: a desconcentração, que se caracteriza pela ocorrência de transferência de responsabilidades administrativas dentro da agência pública central; a delegação, que implica transferência de responsabilidades gerenciais da estrutura burocrática central para organizações externas ou para unidades administrativas dentro de uma região ou para organizações não governamentais e filantrópica; a devolução, considerada como transferência de responsabilidade fiscal e administrativa para as unidades sub-nacionais de governo ou para autoridade regional ou local dentro de unidades administrativas; e a privatização, que se refere à transferência de responsabilidades públicas para órgãos privados (Penfold-Becerra,1998: 6).

Há ainda uma outra tipologia frequiente na literatura, definida de acordo com as modalidades apresentadas pela descentralização. Nessa tipologia, a descentralização pode ser funcional, quando são transferidas ao ente descentralizado competências especificas, ou delimitadas, quando se referem a só um setor de atividade. Ela é territorial, quando é transferido poder decisório a órgãos cujo âmbito de atuação ou cuja jurisdição estão constituídos por um território, ainda que esses órgãos, tendo personalidade jurídica própria, mantenham uma relação de dependência hierárquica na geração de suas autoridades. Finalmente, a descentralização política, considerada como a forma máxima da descentralização, quando o corpo descentralizado é gerado a partir de processos eleitorais e se pode reconhecer uma estrutura administrativa descentralizada, a exemplo dos municípios, províncias, departamentos etc.(Boisier,1991:32) ${ }^{6}$.

Todas estas tipologias têm sido objeto de críticas e consideradas apenas um exercício de taxinomia, não ajudando muito a entender o processo de descentralização como um todo, suas interfaces e complexidade. Além disso, a descentralização é um processo dinâmico, que envolve transferência de poder, portanto, gerador de conflitos e disputas, aspectos difíceis de serem contemplados em tipologias. Boisier(1991), por exemplo, argumenta que nas tipologias anteriormente citadas a questão do poder não é bem dimensionada e a descentralização é apresentada como uma proposta que se restringe apenas a iniciativas do governo central para mudar as estruturas de tomada de decisão, transferindo responsabilidade para outras esferas de governo ou outras organizações.

Ainda no esforço de síntese pretendido neste ensaio, e tomando de empréstimo as constatações de Boisier(1991), observam-se certos paradoxos quanto ao uso dos argumentos a favor ou contra a descentralização na produção teórica sobre o tema. Boisier (1991) considera que existem erros de sinonimia, isto é, são utilizados termos diferentes como equivalentes (devolução, desconcentração etc.); erros tipológicos, que ocorrem em função do mal uso das diferentes modalidades de descentralização (funcional, territorial e política); erros políticos, quando a maioria dos trabalhos não estabelece uma relação clara entre a descentralização e a democracia, não atentando para o fato de que a descentralização é condição necessária mas não suficiente para a prática democrática. Há ainda erros de lógica processual, ao se verificar que muitos autores atribuem um caráter linear e unívoco ao processo de descentralização, desconhecendo seu caráter dialético, e esquecendo que o mérito da descentralização política não deve ser atribuído a nada em particular, pois é mérito da sociedade em seu conjunto. Um outro equívoco comum observado na literatura sobre o tema é o axiológico, ou seja, aborda-se a descentralização ou como instrumento ou como fim em si mesmo. Tal abordagem, a maioria das vezes, implica um juízo de valor e ético, tornando difícil sua precisão conceitual (p:30-36).

Mesmo levando em conta a diversidade de abordagens sobre o tema descentralização e

${ }^{6}$ Estas modalidades, segundo Boisier(1991), podem aparecer de forma pura ou mista e deve sempre levar em conta a existência de duas pessoas jurídicas sem relação de dependência. 
as diferentes fórmulas jurídico-institucionais requeridas para $\mathrm{o}$ processo de sua implementação, existe um certo consenso em torno de idéias centrais, como transferências de recursos financeiros e de poder decisório, controle social sobre a aplicação de recursos, aumento de responsabilidades e das competências locais.

Entretanto, este consenso ainda não soluciona uma certa tensão presente na discussão sobre o tema, fruto da polarização com seu outro extremo, a centralização. Esta situação é analisada no estudo de Vieira (1971:77). Ao buscar construir uma teoria da descentralização, considera ele que a "a análise do problema geralmente tem sido baseada numa posição doutrinária apriorística: descentralização é bom; centralização é mau", e adverte que "o continuum centralização x descentralização deve ser estudado globalmente" (Vieira,1971:77). Por sua vez, Bobbio (1986) chama atenção para o fato de que a centralização e a descentralização, mais do que institutos, são fórmulas que contêm princípios e tendências, daí porque elas dificilmente existem no Estado Moderno de forma pura" (1986:27).

Esta concepção, mais próxima do campo das ciências políticas, parece ser também a mais prevalecente nos estudos sobre as experiências de descentralização nas sociedades contemporâneas, conforme já registrada anteriormente na referência da obra de Burdeau (1980). Estas experiências reforçam que as transferências intergovernamentais, decorrentes tanto dos processos de descentralização quanto do próprio federalismo, são processos dinâmicos e conflituosos, principalmente em realidades tão desiguais quanto as dos países em desenvolvimento, em particular dos países do continente latino americano.

Isto explica, por exemplo, as oscilações entre momentos centralizadores e descentralizadores verificadas em determinadas realidades sociais, como a que se apresenta no sistema político brasileiro, cuja história é marcada, na visão de Souza,C.(1992), pelo predomínio de arranjos institucionais centralizadores, até o início da redemocratização, colocando os governos estaduais e municipais em constante dependência do governo federal. Esta situação vai tendendo a se reverter a partir da Constituição de 88, quando a descentralização passa a ser a espinha dorsal das reformas constitucionais em curso nesta década no Brasil.

Tais constatações partem do reconhecimento de que as ambigüidades e contradições que perpassam a discussão do tema na literatura são mais um indicativo do quanto esta questão, mesmo tendo determinantes estruturais, tem seus resultados e sua amplitude condicionadas por determinantes conjunturais e pelas visões de mundo que informam os projetos descentralizadores.

\section{IV - A Descentralização no campo da saúde no Brasil}

No campo específico da saúde, a descentralização tem sido também um tema privilegiado na literatura específica da área da saúde no Brasil. Vale lembrar que a descentralização dos serviços de saúde, enquanto estratégia para a organização da prestação de serviços de saúde, está presente desde muitos anos, não só no âmbito da produção acadêmica como dos projetos institucionais de vários governos, transformando este setor no mais emblemático do Brasil na defesa desta proposta e contemplando uma variedade de concepções e de desdobramentos teóricos e práticos.

À semelhança do que se vê na discussão geral do tema na literatura internacional, no campo da saúde o debate brasileiro também mantém a marca ambígua e contraditória, com diferentes entendimentos e aplicações, além de diferentes focos de análises. Assim, mesmo correndo os riscos das classificações, pela possibilidade do "aprisionamento" da diversidade presente no debate, é possível observar, conforme apresentado no Quadro 2, três grandes vertentes, a saber: a que discute a descentralização como forma racional de organização da oferta de serviços de saúde e da aplicação de recursos financeiros; a que a concebe como um 
conceito estratégico das reformas políticas da saúde, com vistas à redemocratização do setor. ${ }^{7}$ E a terceira que discute a descentralização a partir da análise dos enfretamentos políticos, das intermediações de interesses e das possíveis tendências do projeto de reforma política da saúde no Brasil.

A primeira vertente, informada pela racionalidade técnico-administrativa, discute a descentralização da saúde enquanto forma de organização do sistema nacional de saúde e o papel de cada uma das instâncias do sistema, em particular da esfera local, concebida como executora das ações de saúde. Esta vertente é mais típica dos estudos clássicos de administração de saúde, como os conhecidos trabalhos de Hanlon (1963), Ferrara (1976) Merino(1977), Molina (1977) e San Martin (1977), estando presente ainda hoje em muitos estudos sobre a descentralização da saúde, principalmente naqueles com preocupações mais prescritivas (OPS/OMS,1987; Mils,1990) ou que tratam das formas e procedimentos relativos às transferências de recursos financeiros para a saúde entre esferas de governo(Viana et al.1991; Piola,1993; Médici,1996).

A segunda vertente tem sido predominante nos estudos da área, particularmente a partir das reformas do setor saúde iniciadas na década de 80, quando a descentralização tornase tema privilegiado de estudos, tanto da academia como de instituições de pesquisa e de prestação de serviços da área de saúde. Esta vertente se divide em três grandes linhas. A primeira delas discute o tema da descentralização da saúde, enquanto princípio norteador do processo de reformas políticas da saúde, articulado com as reformas mais amplas do Estado, e que se instaurou no Brasil e no mundo a partir dos anos 80 (Cohn,1994; Castro,1992; Fleury, 1990; Fundap,1988; Silva,1989; Teixeira,1991, Goulart,1994; Mendes,1993; Muller, 1991).

A segunda linha, privilegia o estudo do nível local do sistema da saúde, ou seja, o estudo sobre a municipalização da saúde propriamente dita. Os municípios, a partir da Constituição de 88 e da criação do SUS, em 90, passam a se constituir na esfera de governo responsável pela gestão local do sistema nacional de saúde. Nesta âmbito, observa-se que os estudos realizados contemplam a avaliação do grau de descentralização da saúde alcançado em determinadas regiões do país, através de indicadores que dimensionam o quanto se transferiu de recursos técnicos, administrativos e financeiros para os municípios gerirem o sistema de saúde local, quais os resultados destas transferências, e se elas estão contribuindo ou não para a construção do SUS, conforme seu desenho original (Abreu et al,1995; Draibe, Sônia (1996), Helmann et al,1992; Queiróz,1994; Workman,1994; Tanaka et al, 1991).

A terceira linha surge com mais intensidade na década de 90 e privilegia o estudo sobre as instâncias colegiadas de decisão do sistema de saúde, ou seja, os conselhos de saúde, criados desde as AIS, em 1992, e ampliados e formalizados como parte da estrutura do sistema nacional de Saúde, a partir do SUS. Os conselhos municipais de saúde são os mais privilegiados até o momento, recebendo análise apurada de suas funções, de seu funcionamento, além dos tipos de participação e de participante neles presentes, com base em estudos empíricos (Carvalho,1995; Ramos,1995; Cortes,1995; Pinheiro,1995; Nescon/MG, IBAM, IMS/UERS et al, 1991). Muitos desses estudos apontam para a ocorrência de uma ampliação da participação social no processo de decisão das prioridades locais de saúde em determinadas conjunturas, a exemplo dos estudos realizados no município de Porto Alegre, no Rio Grande do Sul (Cortes, 1995) e em municípios do Rio de Janeiro (Pinheiro,1995).

\footnotetext{
${ }^{7}$ Na revista Saúde em Debate , editada pelo Centro Brasileiro de Estudos da Saúde - CEBES, fundado em 1976, considerada como um veículo privilegiado para a formação das base intelectuais e programáticas do "movimento" da Reforma Sanitária no Brasil, há um grande número de artigos publicados sobre o tema descentralização. Citá-los aqui constituiria uma tarefa que extrapolaria os limites da revisão de literatura proposta para este ensaio. Ver estudo realizado por Guimarães e Santos(1996) sobre os tipos de artigos publicados por esta revista, nos seus 20 anos de existência . Este estudo evidencia a presença, de artigos sobre o tema descentralização, em quase todos os números da revista durante a década de 80 e início de 90. O tratamento dado ao tema transita entre as duas vertentes levantadas pela revisão de literatura sobre a descentralização da saúde aqui apresentada.
} 
Durante os anos de 1997 e 1998, resultados de pesquisa sobre a implantação da descentralização do sistema de saúde começam a ser apresentados no nordeste e no estado da Bahia (Molesini,1996). ${ }^{8}$ Nesse particular, ressalta-se o trabalho realizado pelo IPEA/SEI(1998) sobre a descentralização no Brasil, incluindo o estudo da descentralização das políticas sociais de saúde e saneamento na Bahia. Este estudo apresenta os resultados alcançados no Estado, no período de 88 a 96, e as mudanças ocorridas na esfera estadual e municipal do sistema de saúde. Suas conclusões apontam para o fato de que, embora sejam observados avanços em alguns "programas', como o aumento do número de municípios habilitados em alguma forma de gestão do sistema de saúde, e de municípios com conselhos municipais de saúde formados e atuantes, "tanto nas relações da Secretaria Estadual de Saúde(SESAB) com o Ministério da Saúde, quanto nas relações da Secretaria Estadual com os Municípios, o que de fato ocorreu no período estudado foi uma desconcentração de recursos financeiros, sem que a SESAB, no primeiro caso, e os Municípios, no segundo, ganhassem um grau de autonomia (capacidade de decisão) sobre a condução do sistema estadual e dos Sistemas Municipais de Saúde" (p:40).

Há ainda nesta linha, trabalhos mais recentes que têm procurado demonstrar o peso determinante dos atributos estruturais das unidades locais de governo para a descentralização. Exemplo de tais atributos são a capacidade fiscal e administrativa e a cultura cívica local, dentro de um estado federativo como o brasileiro, caracterizado por expressivas desigualdades estruturais de natureza econômica, social, política, e da capacidade administrativa de seus governos (Arretche,1998:2).

Neste contexto, o trabalho de Arretche(1998) analisa os fatores que têm determinado a descentralização das políticas sociais no Brasil, em particular as de saúde, de saneamento e de assistência social, em seis estados brasileiro, entre os quais três do nordeste: Bahia, Pernambuco e Ceará. Os resultados indicam diferentes 'graus' de descentralização (baixo, médio e alto) em cada estado estudado, revelando diferenças na extensão do processo de transferência de atribuições em cada 'programa' observado. A Bahia, Pernambuco e o Rio Grande do Sul foram os Estados que obtiveram os mais baixos escores globais da amostra (os outros estados da pesquisa foram São Paulo, Ceará e o Paraná).

A terceira vertente de estudos passa também pela descentralização, embora não analise diretamente o tema. Trata-se da análise do próprio processo das reformas políticas na área social, particularizando a saúde, e que discute os enfrentamentos políticos, as intermediações de interesses e as tendências prováveis de tais reformas para o final deste século. Alguns destes estudos analisam a trajetória dessas reformas em conjunturas específicas (Cohn,1989; Luz,1991; Melo,1993) e outros que apontam para a viabilidade política futura das mesmas (Almeida,1996; Viana, L.D’Ávila1996), analisando os principais obstáculos e confrontos entre atores políticos presentes no processo de implementação da reforma da saúde, particularmente a implantação do SUS nos anos 90 (Noronha e Levcovitz,1994). Na vertente em causa, é importante registrar alguns artigos destoantes do consenso geral presente na literatura da saúde coletiva, que se colocam mais reticentes quanto à estratégia da descentralização no Brasil. É relevante aqui o artigo de Paim (1991) que não vê a descentralização como um caminho exclusivo nem excludente, embora admita ser ela fundamental para a organização de sistemas de saúde mais eficientes e eficazes. $O$ autor considera que o poder local não é, intrinsecamente, mais democrático, podendo ser despótico

\footnotetext{
${ }^{8}$ Em final do ano de 1996, Molesini(1996) apresentou um projeto de dissertação de mestrado com o objetivo de avaliar a municipalização da saúde na Bahia. Esta dissertação foi finalizada no inicio do ano de 1999.

${ }^{9}$ No trabalho de Arretche(1998) a autora considera que o SUS por ser um grande projeto de reforma na área de saúde, a analise dos seus resultados evolve a descentralização de uma variedade de ações em saúde, e por esta razão, adota a categoria 'programa', que será adotada também neste trabalho, para referir a uma das dimensões do projeto maior, e que possa ser simultaneamente a mais representativa possível do processo de descentralização em curso e mensurável por indicadores de cobertura ou capacitação institucional (p:6)
} 
como qualquer outro, do mesmo modo que o poder dos Estados e da União não está condenado inexoravelmente ao autoritarismo ou à ditadura, concluindo que "a municipalização não significará necessariamente democratização"(Paim,1991:28).

Outro trabalho também importante nesta direção é o de Arretche(1996), que se propõe a desmitificar as possíveis virtudes da descentralização, ao analisar a implantação da municipalização de políticas sociais no município de São Paulo: a habitacional, a da assistência social e a da saúde. A autora, mesmo admitindo que é no campo dos programas de saúde pública que ocorrem as mais bem sucedidas experiências em direção a uma reforma de tipo descentralizador, conclui afirmando que não há uma relação necessária entre descentralização e democratização do processo decisório, nem entre descentralização e redução do clientelismo, pois esta redução "supõe a construção de instituições que garantam a capacidade de enforcement do governo e a capacidade de controle dos cidadãos sobre as ações deste ultimo"(p.62) ${ }^{10}$.

\footnotetext{
${ }^{10}$ Em relação às políticas habitacionais, a autora conclui que a sua municipalização não implicou maior controle social sobre a distribuição de recursos públicos, nem criou mecanismos automáticos para evitar sua utilização como instrumento de patronagem política; diferentemente, neste caso, a oferta de um benefício social (caro e altamente subsidiado) representou um elemento - entre outros - no interior de uma estratégia de reprodução e/ ou manutenção de um partido político no controle do governo do estado"(Arretche,1996:62).
} 
V - Conclusões

A partir da revisão da literatura aqui apresentada sobre o tema da descentralização, pode-se ressaltar, como achado mais importante, o consenso em torno da sua necessidade, pertinência, oportunidade e capacidade estratégica para superação dos conflitos de distribuição de poder, de serviços e de recursos entre esferas de governos e/ou setores da sociedade.

$\mathrm{Na}$ maioria dos trabalhos que analisam processos específicos de descentralização de políticas públicas sociais, como o caso da municipalização da saúde no Brasil, observa-se uma clara defesa não só da sua necessidade como até da sua suficiência para superação dos problemas enfrentados pelo sistema de saúde do país, mesmo reconhecendo dificuldades na sua implementação e admitindo tratar-se de um processo de natureza eminentemente político. Assim, ao se contrapor à descentralização, há sempre o risco de estar se colocando também contra a princípios democráticos, face à inequívoca associação que se construiu entre ela e a idéia de democracia, como explicita Blanco(1994): "quem se opõe a uma sociedade mais aberta e livre também se opõe à descentralização"(p.123), Trata-se, como admite Boisier(1991), de um tema que, como o da liberdade, democracia e família, goza de dois privilégios: o de ninguém se declarar contra ele e o de poucos se comprometerem efetivamente com ele, ou como afirma Souza,C.(1996), a razão do sucesso da descentralização está no fato dela prometer mais do que pode efetivamente cumprir.

De fato, se se considera que a descentralização possui uma "forte carga simbólica própria que permite sua manipulação em contextos discursivos diversos, produzindo efeitos e sentido particulares", conforme conclusões de Tobar(1991:31), o debate conceitual observado na literatura pode estar refletindo, na verdade, visões de mundo e inclinações ideológicas de seus autores.

Diante disso, conforme mapeou Souza,C(1995), ainda não se observa um consenso em torno dos caminhos pelos quais a discussão teórica deve ser encaminhada para se construir um conceito de descentralização que supere os problemas identificados nas concepções atuais.

A tendência atual do debate sobre a descentralização parece apontar para uma articulação entre a dimensão normativa, que privilegia a discussão sobre arranjos institucionais, e a dimensão política, que privilegia os embates e confrontos de poder, tanto entre níveis de governo, como entre atores políticos e sociais distintos. Esta tendência parte do reconhecimento de que a descentralização afeta as relações de poder e introduz novos conflitos nas relações entre esferas de governo e entre grupos distintos da sociedade, não podendo, portanto, ser concebida apenas na sua dimensão formal/legal.

Nesse sentido, o continuum descentralização-centralização é estratégico para as reformas institucionais e políticas que vêm ocorrendo nos países da América Latina, particularmente no Brasil. Os estudos sobre as reformas políticas destes países demonstram que a ênfase dada à descentralização nas últimas décadas é fruto dos seus processos de redemocratização e sua adoção como política de governo visa legitimar novos regimes políticos e serve como meio para repensar novos arranjos institucionais dos seus respectivos sistemas políticos. 


\section{REFERÊNCIAs BIBLIOGRÁFICAs}

ABREU, Daisy et al . Descentralização da Saúde e Poder Local em Minas Gerais. In:

I CONGRESSO BRASILEIRO DE CIÊNCIAS SOCIAIS EM SAÚDE, Trabalho apresentado na mesa redonda : Avaliação de Políticas e Serviços de Saúde: o olhar das Ciências Sociais. ABRASCO/NESCO-PR/SES-PR, Curitiba-PR, agosto, 1995. (mímeo)

AFONSO, José Roberto Rodrigues, LOBO, Tereza. Descentralização Fiscal e Participação em Experiências Democráticas Retardatárias'. Artigo apresentado no TINKER FÓRUM ON THE ROLE OF STATE IN LATIN AMÉRICA AND CARIBBEAN, Cancún, México, 24-26 de outubro,1996. (mímeo).

AFONSO, Rui de Brito Álvares e SILVA, Pedro Luíz Barros (org). Descentralização e Políticas Sociais. São Paulo: FUNDAP. Série Federalismo no Brasil, p:376. 1996.

ALMEIDA, Maria Hermínia Tavares. Federalismo e Políticas Sociais, In: AFONSO, Rui de Brito Álvares e SILVA, Pedro Luiz Barros (org.) Descentralização e Políticas Sociais. São Paulo: FUNDAP. Série Federalismo no Brasil,1996. p.p:13-37.

AROCENA, José. Algunas Dimensiónes del concepto de descentralización. In: Nohlen, Dieter (ed.) Descentralización Política y consolidación democrática, Europa- América del Sur. Venezuela: Nueva Sociedade,1991.p.17-22.

Descentralización e Iniciativa: Una Decisión Necesária. In:Cuadernos del Claeh 50:42-55,1989.

ARRETCHE, Marta. Mitos da Descentralização: Mais Democracia e Eficiência nas Políticas Públicas. In: Revista Brasileira de Ciências Sociais. AMPOCS, n. 31, ano 11. Jun.1996. p.p.44-66.

Políticas Sociais no Brasil: Descentralização em um estado federativo'. UNESP, São Paulo. Apresentado no XXI encontro da Associação de estudos latino americano. Chicago, Iilinos, set.1998. p.p.24-26 (mímeo).

BAÊTA, A Ma C Administração municipal e descentralização política. Notas para uma discussão. Revista de Administração Pública, 23(4).1989.

BENNETT, Robert. J. Decentralizatión Local Governments, and Markets- Towards a Post- Welfare Agenda. New York: Oxford University Press, 1990.

BLANCO, Carlos Refoma y modernización del Estado en América latina: hacia un nuevo proyecto latinioamericano'. In: ILPES- Instituto Latino Americanio y del Caribe de Planificación Económica y social'Reforma y Modernización del Estado'. Santiago de Chile: Comission Ecnómica para America latina y el Caribe- Naciones Unidas, p.p.109-154, 1994.

BOBBIO, Noberto et al. Dicionário de Política . Brasília: Universidade de Brasília,1986.

BOISIER, Sérgio. La Descentralización: un tema difuso y confuso. In: Nohlen, Dieter (ed.) Descentralización Política y consolidación democrática, Europa- América del Sur. Venezuela: Nueva Sociedade,1991.p.22-39.

BORJA, Jordi. Desentralización : Una Questión de Método. In: Revista Mexicana de Sociologia, México, 4:.5-33, 1984.

.A paticipación citadina. In: Revista Espaço \& Debate, São Paulo, (8)24 :14-25,1988.

BORGONOVI, Hélio. Cultura manageriale, programazione e governo locale. In: Rev. Univewrsitá Comerciale Luigi Bocconi ANCI n .9, Milão,1985.

BURDEAU, Georges. Traité de Science Politique. Deuxieme Edition. Tome II L’Etat . Paris: L.G.D.J, 1967.

CASTRO, Maria Helena Guimarães de. Descentralização e Política Social no Brasil: as perspectivas dos anos 90. In: Revista Espaço \& Debate, São Paulo, n. 32, 1991.

COSTA, A.C. L. Autonomia no Município na Atual Constituição. In: Revista Espaço \& Debate, São Paulo, (3)19, 1986.

COSTA, Nilson do Rosário e SILVA, Pedro Luís Barros, RIBEIRO, José Mendes. A descentralização do sistema de Saúde no Brasil. In: Revista do Serviço Público, São Paulo, ano 50, Número 3, jul-set,1999.

COSTA, Nilson do Rosário .Conflitos e interesses na implementação da Reforma da política de saúde. In: Revista Saúde em Debate, Londrina-PR: CEBES, n. 35: 15-22,1992.

CARVAlHO, Antônio Ivo.Conselhos de Saúde no Brasil: Participação Cidadã e Controle Social. Rio de Janeiro: FASE/IBAM,1995. 136p. 
CARVALHO, Inaiá. Descentralização e Políticas Sociais. In: Caderno CRH. Salvador, n.26/27, p.75-105, jan/dez 1997.

CAMPOS, Gastão Wagner de Souza. Um balanço do processo de Municipalização dos Serviços de Saúde do Brasil. In: Revista Saúde em Debate. Londrina-PR, n.28,mar.,1990, p.24-28.

COELHO, F.Dias . Descentralização e democratização da esfera Pública. In: Anais do V Encontro Nacional da AMPUB (1): 992-1001, agosto,1993.

COHN, Amélia. Caminhos da Reforma Sanitária. In: Revista Lua Nova, n.19, p.1989

. Descentralização, Saúde e Cidadania’. In: Revista Lua Nova. n.32,p.15,1994.

Saúde e Cidadania: Análise de uma Experiência de Gestão Local. In: Eibenschutz.Catalin (org) Política de Saúde: O público e o Privado, Rio de Janeiro: Fio Cruz, 1996, p.315-329.

. Mudanças econômicas e políticas de saúde no Brasil. In: LAUREL, Asa Cristina (org.). Estado e Políticas sociais no neoliberalismo. $2^{\text {a }}$ ed. São Paulo: Cortez, 1997.p.225-244.

CORTES, Soraya Maria Vargas . User Participation and Reform of the Brasilian Health System: The case of Porto Alegre'. Thesis of Doctor of Philosophy, The London School of Economics and Political Science Department of Social Policy and Administration . Londres, 1995a.

CUNHA, R E. da. Os caminhos da municipalização de saúde no Brasil'. In: Revista Espaço para a Saúde, 1(0): 7-9,1994.

D'ARC, Riviére, Hélène. La Decentralizatión de l'Etat'. In: COUFFIGNAL Georges (org.) Réiventer la democratie- le defi latino -americano. Paris: Presses de la Fundation Nationale des Sciences Politiques, 1992.

DANIEL, Celso. Poder Local no Brasil Urbano. In: Revista. Espaço \& Debate 24,1988.

DAVIDOVICH, Fany. Poder Local e Municípios, Algumas Considerações. In: Revista de Administração Pública, Rio de Janeiro, 27(1):5-14,1993.

DAWBOR, Ladislaw. O Novo Contexto da Gestão Local. In: SANTOS,Alexandre C. de A e GARCIA, Romary C (org,) (1993) Anais do Seminário Municipalização das Política Públicas: Convênio IBAN/IPEA/ENAP. Rio de Janeiro, 1993.p.102-110.

DRAIBE, Sônia.Avaliação da Descentralização das Políticas Sociais no Brasil: Saúde e Educação Fundamental'. Estudo Preparatório, Projeto: Estúdios de Descentralización de Servicios Sociales, CEPAL Centro de Planejamento da América Latina, División de Desarollo Econômico ,UNICAMP Universidade de Campinas, NEPP, Núcleo de Estudos em Políticas Públicas,1996a.

.Avaliação da Descentralização das Políticas Sociais no Brasil: Saúde e Educação Fundamental'. Projeto: Estúdios de Descentralización de Servicios Sociales, CEPAL/UNICAMP/NEPP,1996b.

ELAZAR, Daniel, J. ências Centralizadoras e Descentralizadoras dos Sistemas Federativos Contemporâneos: Uma Análise Preliminar'. In: Revista de Administração Pública. Rio de Janeiro, 28(159) 64-84,abr/jun,1981.

FERREIRA, Djalma e Proserpio, Renata A Renda dos Município Baianos. Análise \& Dados, Retrospectivas 1996 e Perspectivas, SEI 6 (.3):21-24.1996.

FELICÍSSIMO, R J. Os impasses da descentralização política administrativa na democratização do Brasil. In: Revista de Administração de Empresa, n. 32(1),1992.

Empresa (3),1994.

América Latrina: movimentos sociais frente à descentralização do Estado. Revista de Administração de

FERRARA, F.A, ACEBAL, E; PAGANINI, J.M (org.).Medicina de la Comunidad: medicina preventiva, medicina social medicina administrativa. $2^{\mathrm{a}}$. edição, Buenos Aires: Inter. Médica, 1976.

FILHO, C P; Rezende, F ; MARINHO, G. Descentralização. Valorização da Esfera Pública?. In: Anais do V Encontro Nacional da AMPUR, n. $1: 420-430,1993$.

FIORI, José Luis. Globalização econômica e descentralização política: um primeiro balanço. In: Ensaios FEE, Porto Alegre, Ano $15, \mathrm{n}^{\circ} 2$.

FLEURY, Sônia Teixeira. Descentralização dos Serviço de Saúde : Dimensões Analíticas. In: Revista de Administração Pública, Rio de Janeiro: 24(2): 78-99, 1990. 
FRANÇOIS, D’Arcy et BAENA del Alcazar. Decentralizacion en France et en Espanhe. Paris: Ed. Economia,1986.

FUNDAP Fundação do Desenvolvimento Administrativo. Perspectivas Institucionais da Descentralização na Saúde, DT/24 , São Paulo,1988.

GOULART, Flavio, A de Andrade. Municipalização: veredas caminhos do movimento municipalista de saúde no Brasil. Rio de Janeiro:ABRASCO/CONASEMS,1996.

Risco ou Oportunidade? O momento Presente da Municipalização da Saúde no Brasil. In: Revista Espaço

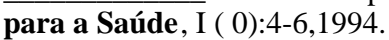

GUIMARÃES, Maria do Carmo Lessa e SANTOS, Sandra Maria Chaves. Temas Emergentes na Administração Pública: Reflexos em Discursos sobre Organização do Setor Saúde. Salvador-Bahia, In: VI Congresso Brasileiro de Pós-Graduação em Saúde Coletiva, 23 ago a 03set.2000.Anais....Salvador CD-ROM.

GONTCHAROFF, George. Democratie, citoyenneté dans la decentralization. Etat des lieux de la citoyenité locale, decentralization e participation. Paris: Revue Territoires, n.321, oct,1990.

HANLON, J. J. Princípios de Administración Sanitária, 2a . edição. México: La Prensa Mexicana,1963.

HEIMANN, .L S et al. O Município e a Saúde. São Paulo: Hucitec,1992.

HERAUD. Guy. De la decentralization au Federalisme'In: Moderne, Frank (dir.).La nouvelle decentralization. Paris: Sirey, (col. Bibliotheque des collectivités locales),1983.

ILPES- Instituto Latino Americanio y del Caribe de Planificación Económica y social. Reforma y Modernización del Estado. Santiago de Chile: Comission Ecnómica para America latina y el Caribe- Naciones Unidas, p.p.109-154, 1994.

IPEA, Instituto de Pesquisa Econômica Aplicada, IBAM, Instituto Brasileiro de Administração Municipal. O novo Pacto Federativo . Rio de Janeiro: IBAM,1994.

JACOBI, Pedro. Descentralização Municipal e Participação dos Cidadão: Apontamentos Para um Debate.In: Revista Lua Nova, 20,1990. n.38(198):32-38,1991.

Os municípios e a participação: Desafios e Alternativas'. In: Revista de Administração Municipal, JÚNIOR, Hugo Mendes. O financiamento do SUS e as emendas à Constituição In: Revista Saúde em Debate, Londrina: CEBES, n.48, p:61:68, set.1995.

LAVINAS, Lena, MAGINA, Manoel Augusto, SILVA, Mônica Couto e. Federalismo e Regionalização dos Recursos Públicos.In: Texto para Discussão, 369 . Brasília. : IPEA, 1995.

LORDELO DE MELLO, Diogo. Descentralização, Papel dos Governos Locais no Processo de Desenvolvimento Nacional e Recursos Financeiros para que os Governos Locais Possam Cumprir seu Papel. In: Revista de Administração Pública, Rio de Janeiro, 25(4) : 199-217, 1991.

LOBO, Tereza. Descentralização: Uma Alternativa de Mudança,. In: Revista de Administração Pública, Rio de Janeiro, 22(1), 1988.

Descentralização e Revisão Constitucional. In: SANTOS,Alexandre C. de A e GARCIA, Romary C (org,) (1993) Anais do Seminário Municipalização das Política Públicas: Convênio IBAN/IPEA/ENAP. Rio de Janeiro, 1993.p. 121-122.

LUZ, Madel Terezinha. Notas sobre as políticas de saúde no Brasil de transição democrática,anos 80. In: Physis. Revista de Saúde Coletiva, v.1, n.1,1991.

MABILEAU,Albert. La Decentralization en retard'. In: L'Etat de la decentralization- Les Cahiers Français. Paris: La Documentation Française, n.256, mai/jun,1992.

MATTOS, Carlos. La Descentralización? Una Nueva Panacéa Para Impulsionar el Desarollo Local?. In: Cuadernos del Claeg, Montevideo :56- 75,1989.

MASSOLO, Alezandra. Em Direção às Bases: Descentralização e Município. In: Espaço \& Debate, n. 24,1988.

MECHEUT, Martine . Le Federalisme est-il pensable pour une Europe prochime?. Paris: Ed. Kimé,1994 
MEDEIROS, Antônio Carlos. The Politics of decentralization in Brazil. In: European Review of Latin American and Caribbean Studies, Amsterdãm, n. 57, december,1994.

MÉDICI, André. Descentralização e Gastos em Saúde. In: AFONSO, Rui de Brito Alvares e SILVA, Pedro Luiz Barros (orgs.) Descentralização e Políticas Sociais,. São Paulo: FUNDAP. Série Federalismo no Brasil, 1996. p. 297-376.

MERINO, R. El Processo de Administración en Salud Pública. In: San Martin, H Salud y Enfermidad: Ecologia Humana, Medicina Preventiva e Social. 3ª edição México : La Prensa Médica Mexicana,1977.

MELO, Marcus André B. C. de. Crise Federativa, Guerra Fiscal e "Hobbesianismo Municipal", Efeitos Perversos da Descentralização?. São Paulo em Perspectiva, Fundação SEADE, v.10, n. 3, p. 11-20, jul./ set. 1996.

Democracia, Neolocalismo e Mal-Estar Social: A Geometria Política da Nova República. In: Agenda de Políticas Públicas, n. 4, Instituto Universitário de Pesquisas do Rio de Janeiro (IUPERJ), 1983.

Anatomia do Fracasso : Intermediação de Interesses e a Reforma das Políticas Sociais na Nova República. In: DADOS, Revista de Ciências Sociais, Instituto Universitário de Pesquisas do Rio de Janeiro (IUPERJ), 36(1):119-163, 1993.

MENDES,E.V (org.).Distrito Sanitário - o processo social de mudança nas práticas sanitárias do Sistema Único de Saúde. São Paulo: Hucitec, Rio de Janeiro: Abrasco. 1993

MILS. Anne et al. Descentralización de los Sistemas de la Salud. Conceptos, Aspectos y Experiências Nacionales. Genebra: OMS, 1990.

MOLESINI, Joana Angélica. A Municipalização dos Serviços de Saúde no Estado da Bahia. Evolução, Situação Atual e Perspectivas 1993-1996-1999. Projeto apresentado à comissão de seleção para o curso de Mestrado em Saúde Comunitária. Instituto de Saúde Coletiva. Universidade Federal da Bahia, 1996.

MOLINA, G G . Introdución a la Salud Pública. Medellin: Universidad Antioquia,1977.

MOTTA, Paulo Roberto. A Participação e Descentralização Administrativa: Lições de Experiências Brasileiras. In: Revista de Administração Pública, Rio de Janeiro, (28) 3,1994.

MULLER Neto, Júlio. Políticas de Saúde no Brasil: A descentralização e seus atores. In: Revista Saúde em Debate. Londrina-PR: CEBES, Número 31, 1991.

Descentralização e Democracia: tópico de um debate, In: Revista Saúde em Debate. Londrina-PR: CEBES, Número 33, dezembro de 1991

NESCON/MG, IBAM, IMS/UERS et al. Relatório Final da Pesquisa: Avaliação do funcionamento dos Conselhos Estaduais e Municipais de saúde. Brasília, 1993(mimeo).

NOHLEN, Dieter (ed.).Descentralización Política y consolidación democrática, Europa- América del Sur. Venezuela: Nueva Sociedade, 1991.

NORONHA, José Carvalho de., LEVCOVITZ, Eduardo. AIS-SUDS-SUS: Os caminhos do Direito à saúde'In: GUIMARÃES, Reinaldo, TAVARES, R (orgs).Saúde e Sociedade no Brasil: anos 80. Rio de Janeiro : Relume Dumará,1994.p.73-111.

OPS/OMS. Descentralizacion de Servícios de Salud. Tema el Estado y los Servicios de Salud. In: Série Desarollo de Servicio de Salud, n.17 .Buenos Aires,1987.

PAIM, Jairnilson. Quando a Municipalização não é o Caminho. In: TEMA/RADIS . Fundação Osvaldo Cruz, p. $27-28,1991$.

PENFOLD-BECERRA,M. Towards a Politcal Theory of Decentralization: Passing the Ball in Venezuela, 1998 [online] Disponível em map43@ columbia.edu.Acesso em: 18 nov.1998.

PINHEIRO, Roseni. Conselhos Municipais e Saúde: O Direito e o Avesso. Dissertação de Mestrado. Instituto de Medicina Social. Universidade Federal do Rio de Janeiro, 1995.

PIERA, A. P. La Descentralización en Montevidéo: un Itinerario Innovador. In: Cuadernos del Claeg. Montevidéo, 62(17): 93-107,1992.

PIOLA, Sérgio Francisco. Municipalização das Políticas : A Experiência da Saúde. In: SANTOS,Alexandre C. de A e GARCIA, Romary C (org,) (1993) Anais do Seminário Municipalização das Política Públicas: Convênio 
IBAN/IPEA/ENAP. Rio de Janeiro, 1993.p.98-101.

PRETECEILLE, Edmond. From centralization to decentralization: social restructuring and French local government. In: PICKVANCE, Chris, PRETECEILlE, Edmond (eds.). State Restructuring and Local Power: A Comparative Perspective. London: Pinter Publishers, 1991. p.123-149.

PRUD'HOMME, R. The Dangers of Decentralization. In: Research Observer. Washington: The World Bank, vol:10(1)fev., 1995.

QUEIRÓZ, M S. O Desenvolvimento da Municipalização dos Serviços de Saúde em Campinas. In: Revista de Administração Pública, Rio de Janeiro, n.(28)4,1994.

RABI, Nídia Albesca. Municipalização dos Serviços Públicos’ In: SANTOS,Alexandre C. de A e GARCIA, Romary C (org,) (1993) Anais do Seminário Municipalização das Política Públicas: Convênio IBAN/IPEA/ENAP. Rio de Janeiro, 1993.p.101-102.

RAMOS, Célia Leitão. Conselhos de Saúde e Controle Social. In: EIBENSCHUTZ, Catalina (org.) Política de Saúde: O público e o Privado.Rio de Janeiro: FIO CRUZ, 1996. p.329-345.

REVEL- MOUROZ, Jean (coord.). Pouvoir Local, Regionalismes, Decentralization- Enjeux territoriaux et Territorialité en Amérique latine. Paris: lÍHEAL/CREDAL, no.47, Série Thèses et Colloques, no.3, 1989.

REZENDE, Fernando. A repartição de Encargos Públicos entre Níveis de Governo. In: Revista de Administração Pública, Rio de Janeiro,18(3),1984.

A descentralização forçada. In: SANTOS,Alexandre C. de A e GARCIA, Romary C (org,) (1993) Anais do Seminário Municipalização das Política Públicas: Convênio IBAN/IPEA/ENAP. Rio de Janeiro, 1993.p.53-57.

ROSANVALLON,Pierre. La decentralization (fin et suite) Entretien avec Rosanvallon. In: Rev.Pouvoir local, n.16, Paris,avril,1995.

RONDINELLI, D.et al. Descentralization in developing countries: a review of recent experience. Washington, World Bank Staff Working Paper, n 581,1983.

RUFIAN, D.M. Una Nueva Administración Municipal. In: Cuadernos del Claeg, Montevidéo-Uruguai, 1992.

SAN MARTIN, H. Salud y Enfermidad: Ecologia Humana, Medicina Preventiva e Social. 3ª edição México : La Prensa Médica Mexicana,1977.

SATO, Ademar. Descentralização; Um Tema Complexo. Texto para Discussão : 314 Brasília: IPEA.1990.

.Descentralização e Pacto Federativo. Centro de Documentação e Informação e Difusão Graciliano Ramos. Brasília: Cadernos ENAP:17-33,1993a.

.O interesse pela descentralização. In: SANTOS,Alexandre C. de A e GARCIA, Romary C (org,) (1993) Anais do Seminário Municipalização das Política Públicas: Convênio IBAN/IPEA/ENAP. Rio de Janeiro, 1993b.p.9-23.

SEI.Superintendência de Estudos Econômicos e Sociais da Bahia. Descentralização no Brasil-Políticas Sociais na Bahia, saúde e saneamento. Salvador: IPEA/SEI, Serie Estudos e Pesquisa , n. 36,1998.

SILVA, Pedro Luiz Barros. Descentralização no Setor Saúde. In: Texto para Discussão 20, São Paulo: FUNDAP, 1989.

Descentralização e crise da Federação. In: AFONSO, Rui de Brito Alves e SILVA, Pedro Luiz de Barros (org.) A Federação em Perspectiva- Ensaios Selecionados. São Paulo:FUNDAP, 1995.p.261-283.

SMITH,B.C. Decentralization: the territorial dimension of the state.London: George Allen \& Unwin Ltda,1985.

SOUZA, Celina. Gestão Urbana. A questão Municipal dos Anos 90. In: Revista de Administração Pública, Rio de Janeiro, 36:30-32, 1990.

Democracia, Participação Social e Funcionamento das Instituições : Situação e Perspectivas da Federalização do Desenvolvimento. In: Revista de Administração Pública, Rio de Janeiro, 26(3):15-35,1992.

Constitutional Change in Brazil: Political and Financial Decentralisation, 1981-1991, Thesis of Doctor of Philosophy. The London School of Economics and Political Science Department of Government, Londres, 1995.

Reeinventando o Poder Local: Limites e Possibilidades do Federalismo e da Descentralização. In: São 
Paulo em Perspectiva, São Paulo, v.10,n.3, jul./set.,p.103-112, 1996

.Intermediação de Interesses Regionais no Brasil: O impacto do federalismo e da Descentralização', In: DADOS, Revista de Ciências Sociais, Rio de Janeiro: IUPERJ, vol.41,no.3,1998.

SOUZA, Manoel Tibério Alves de. Argumentos em torno de um "velho" tema : A Descentralização, In: DADOS, Revista de Ciencias Sociais, Rio de Janeiro: IUPERJ, vol.40,n.3,1997.

SPINK, Peter. Descentralização: Luto ou Luta ?. In: FISCHER. Tânia (org ). Poder local Governo e Cidadania. Rio de Janeiro: Ed. FGV,1993.

TANAKA Osvaldo (1991). A municipalização dos serviços de saúde no estado de São Paulo. In: Revista Saúde em Debate, Londrina-PR: CEBES, n.33, dez. 1991.

TOBAR. F. O. Conceito de Descentralização: Usos e Abusos. In: Revista Planejamento e Política Pública, 5::31-51,1991.

THÉRET, Bruno. Du Fédéralisme et de la protection Socilae en Amérique et en particulier au Canada. Paris: IRIS, Univerisité Paris Dauphine,1995 (mimeo)

TEIXEIRA, Carmem Fontes. Municipalização da Saúde : Os Caminhos do Labirinto. In: Revista Saúde em Debate, Londrina-PR: CEBES, n.33,1991.

UGA, Maria Alicia Dominguez. Descentralização e Democracia: O Outro Lado da Moeda. In: Revista Planejamento e Políticas Públicas, n.5,1991.

VIANNA, Solon Magalhães e PIOLA, Sérgio Francisco. Descentralização e repartição de encargos no sistema único de Saúde- SUS. In: Revista Planejamento e Política Públicas, Brasília, n.5,p.143-16, jun,1991.

Brasília IPEA,1991.

et al. O Financiamento da Descentralização dos Serviços de Serviços. In: Documento de Política, n. 3 .

VIANA, Ana Luíza d' Ávila. SUS: Entraves à Descentralização e Propostas de Mudanças. In: AFONSO, Rui de Brito Álvares e SILVA, Pedro Luíz Barros (org). Descentralização e Políticas Sociais. São Paulo: FUNDAP. Série Federalismo no Brasil,1996.p. 269-295.

VIEIRA, Paulo Reis. Em Busca de uma Teoria de Descentralização. Rio de Janeiro: FGV,1971.

XAVIER-AUBRY. La decentralization contre l'Etat- L'Etat semi-centralisé: nouvel essai. Paris: Libraire Génerale de Droit et des Jurisprudence,1992.

ZANCHETI, M S. Quarto Poder ou Autonomia Municipal?’. In: Revista Espaço \& Debate (3)19,1986.

ZICCARDI, Alicia. El estatus del capital: decentralization, reforma del Estado y federalismo. In: Revista Mexicana de Sociologia, Mexico, n.. 3, jul/set, 1996.

WORKMAN, David. Descentralization in Brasil :case studies of health care and primary education', Instituto of Latin American Studies. University of Texas at Austin, 1994.[online].Disponível em < http:// lanic.utexas.ed...pers9495/workman.html>. Capturado em 26 de agosto de 1996. 